\title{
Production of Raisin from Pre-treated Grapes by Tray Drying
}

\author{
Jain Priti* \\ Department of Post Harvest Process and Food Engineering, College of Agricultural \\ Engineering, JNKVV, Jabalpur, 482004, Madhya Pradesh, India \\ *Corresponding author
}

\section{A B S T R A C T}

\begin{tabular}{|l|}
\hline Ke y w o r d s \\
Immersion Time, \\
$\begin{array}{l}\text { Optimization, } \\
\text { Pretreatment, }\end{array}$ \\
\hline Article Info \\
\hline $\begin{array}{l}\text { Accepted: } \\
\text { 20 August } 2019 \\
\text { Available Online: } \\
\text { 10 September } 2019\end{array}$ \\
\hline
\end{tabular}

\section{Keywords}

Immersion Time, Optimization Pretreatment,

Article Info

20 August 2019

10 September 2019
In this study, raisin was produced from pre-treated grapes by tray drying method. Grapes were cleaned and soaked in a different type of solutions such as potassium carbonate, olive oil, soy lecithin, and sugar concentration for different immersion time. The pre-treated grapes were then dried in a hot air tray drier at $50^{\circ} \mathrm{C}$ and airflow $1.0 \mathrm{~m} / \mathrm{s}$. Results showed that drying time was varied for pre-treated grapes. The shortest drying time of $61 \mathrm{~h}$ ) was obtained for those grapes which were dipped in $6.7 \%$ potassium carbonate solution for immersion time of $5 \mathrm{~min}$.

\section{Introduction}

Grape (Vitis vinifera) is one of the oldest fruit crops in India. In India, among growing commercial fruit crops grape is most important. Dried grapes (raisins) can be eaten raw or used in baking. It has high sugar content (about $20^{\circ}$ Brix), crunchy pulp and thin skin. A good raisin variety should have a soft texture and delightful flavor. Two popular varieties of raisins are Kishmish and Munnakka.

In India, produced fruits are wasted nearly $30 \%$ due to improper post-harvest processing, transportation, and storage (Kumari, 2016). Drying is an important method of food preservation, which provides longer shelf life, lighter weight for transportation and small space for storage (Doymaz, 2007). Though, various methods of drying are adopted by food processors such as vacuum drying, tray drying, tunnel drying, conventional drying process (solar drying), etc. Since grapes contain about $70-80 \%$ water and are perishable in nature. Therefore its shelf life can be increased by drying.

Food products can be treated before processing by several methods viz: blanching, chemical pre treatment, and osmotic dehydration to improve the nutritional quality of the dried products as well as reduce the dehydration time of the drying process (Akanbi et al., 2003; Kingsly et al., 2007). The pre-treated samples dry faster than 
untreated samples and had lower values of the total energy needed and specific energy requirement Pretreatments process removes the wax barrier on fruits or vegetables and thus reduce drying time. It also helps to minimize the nutritional losses in the samples before drying. (Tunde-Akintunde et al., 2014; Doymaz, 2007)

Although there are several studies on drying of grapes was done. But the effect of different concentrations of solution and immersion time for pre-treated grapes on drying time and optimized parameters have been limited. Hence, the objective of this study was to study the production of raisin using tray drying from pre-treated grapes.

\section{Materials and Methods}

\section{Selection of Raw Materials}

Fresh grapes were purchased from a local market of Jabalpur, (M.P.), India. The selected grapes were graded according to size and colour to obtain uniform quality. Then, they were washed with water and unwanted material like dust, dirt, and surface adhering were removed.

\section{Preparation of Sample and Solution}

The cleaned and graded grapes were pretreated in a different solution for different immersion time. The pretreatment was used to develop cracks in the waxy layer of the grapes. Four types of solutions were used with different concentrations: $\mathrm{K}_{2} \mathrm{CO}_{3}$ solution, soy lecithin solution, olive oil solution and sugar solution, which were prepared in distilled water and heated at $50{ }^{\circ} \mathrm{C}$. Then, grapes were soaked in these solutions under continuous agitation for specific immersion time. The total soluble solids of sugar solution were found out by using a hand refractometer, which gives the reading directly in Brix. (Patil et al.,2015; Ranganna, 2000). Finally, the ready samples were weight before drying.

\section{Measurement of Initial Moisture Content}

The moisture content of fresh samples was determined by using an air oven method and calculated by using the following equation. Cool the dried sample in desiccators and weighed. The weight of the sample before and after drying was taken and loss in weight was calculated. Moisture content $(w b)$ of samples was calculated by the following formula:

Moisture content (\%,w. b. )

(Initial mass of sample, $\mathrm{g}$ - final mass of the sample, g) $X 100$

Initial mass of the sample, $\mathrm{g}$

\section{Drying Procedure}

The pre-treated grapes were dried in a hot air tray dryer at $50^{\circ} \mathrm{C}$ with an air velocity of $1 \mathrm{~m} / \mathrm{s}$. The weighed samples were spread in the form of a thin layer of perforated sieves made of steel mesh. Weight loss of the dried grapes was measured at various time intervals, ranging from $30 \mathrm{~min}$ to achieve a moisture content of $14 \%(\mathrm{wb})$, and then the drying process was stopped. The experiments were replicated thrice, and the average of the drying time for each pre-treatment was used for statically analysis.

\section{Statistical Design}

The influence of two independent variables i.e. solution concentration and immersion time on drying time for grapes was analyzed by using central composite rotatable design. All independent variables were controlled at three different levels discussed in Table 1. A second-order polynomial equation was then used to fit the measured, dependent variable (drying time) as a function of the drying parameter. Response Surface Methodology (RSM) which explores the relationship between several explanatory variables and 
response variable was applied to the experimental data using the trial package, Design expert version 11 (Stat-ease Inc., USA). The process was optimized for the minimum value of drying time conducting statistical analysis.

\section{Results and Discussion}

During pre-treatment of grapes, attention was drawn to the necessary concentration of solution and immersion time to increase water vapour permeability through the waxy layer of grapes. The initial moisture content of $84 \%$ (wb) for fresh samples was determined by using an air oven method.

\section{Effect of Different Solution Concentration and Immersion Time on Drying Time}

The variation of drying time was studied against the variation of solution concentration and immersion time to achieve the final moisture content of $14 \%$ (wb) for the grapes is shown in Figure 1 to 4 . These figures show that drying time was reduced with increasing pre-treatment concentration and immersion time. This may be due to the fact that pretreatment accelerates drying rates because the presence of the cuticular wax is the main barrier to the evaporation of water. Removal of the surface wax by pretreatment is effective in promoting evaporation. Gabas et al., 1999 and Pangavhane et al., 1999 also reported that dipping of grapes in pretreatment removes part of the wax and probably destroys the cuticular structure, whereby the drying rate is increased. Dipped grapes stay yellow-green. This is due to the inhibition of the action of the polyphenol oxidizes by quick drying. The waxy cuticle of grape skin controls the rate of moisture diffusion through the berries and accelerates drying. Chemical treatments are applied to remove or modify this cuticle and increase grape permeability to water.
Statistical analysis revealed that drying time was significantly affected by different solution concentration and immersion time. Regression coefficient $\left(\mathrm{R}^{2}\right)$ and $\mathrm{p}$ value were observed with the range of 0.97 to 0.99 and 0.0001 to 0.0117 respectively.

The polynomial equations of second order generated by multiple regression analysis using CCRD for different combination of solution concentration and immersion time are as follows:

Drying time $=146.44-2.75 \times(B)-10.96 \times(A)$ $+0.06 \times(\mathrm{B}) \times(\mathrm{A})-0.1 \times(\mathrm{B})^{2}-0.48 \times(\mathrm{A})^{2}$

Drying time $=213.7-25.15 \times(\mathrm{C})-0.48 \times(\mathrm{A})+$ $0.13 \times(\mathrm{C}) \times(\mathrm{A})+1.4 \times(\mathrm{C})^{2}-0.004 \times(\mathrm{A})^{2}$

Drying time $=144.56-4.14 \times(\mathrm{D})-16.9 \mathrm{x}(\mathrm{A})-$ $0.075 \times(\mathrm{D}) \times(\mathrm{A})+0.33 \times(\mathrm{D})^{2}+1.58 \times(\mathrm{A})^{2}$

Drying time $=200.9-1.76 \times(\mathrm{E})-0.93 \times(\mathrm{A})-$ $0.015 \times(\mathrm{E}) \times(\mathrm{A})+0.014 \times(\mathrm{E})^{2}+0.01 \times(\mathrm{A})^{2}$

Where, $\mathrm{A}=$ Immersion time, $\mathrm{B}=$ Potassium Carbonate, $\mathrm{C}=$ Olive oil, $\mathrm{D}=$ Soy lecithin and $\mathrm{E}=$ Sugar concentration

As per figure 1, optimum potassium carbonate concentration and immersion time for minimum drying time of $61 \mathrm{~h}$ was observed to be $\quad 6.7 \%$ and $5 \mathrm{~min}$ respectively. Figure 2 shows that the sample of grapes treated with $2.79 \%$ olive oil took minimum drying time of $83.3 \mathrm{~h}$ at min immersion time of $120 \mathrm{sec}$. This may be due to higher concentration of solution resulted in cracks development of waxy layer of grapes by which drying rate becomes faster.

From figure 3 it can be inferred that an increase in the percentage of soy lecithin results in lesser drying time. Optimum soy lecithin (3\%) and immersion time (4 min) for minimum drying time $(92 \mathrm{~h})$ were observed. The influence of sugar concentration and immersion time on the drying time for grapes is shown in Figure 4. 
Table.1 Independent variables with their range and levels for vacuum drying

\begin{tabular}{|c|c|c|c|c|}
\hline \multirow[t]{2}{*}{ Set of experiment } & \multirow{2}{*}{$\begin{array}{l}\text { Independent } \\
\text { variables }\end{array}$} & \multicolumn{3}{|c|}{ level } \\
\hline & & -1 & $\mathbf{0}$ & +1 \\
\hline \multirow{2}{*}{$\begin{array}{l}1^{\text {st }} \text { set: Effect of } \mathrm{K}_{2} \mathrm{CO}_{3} \text { concentrations } \\
\text { and immersion time }\end{array}$} & $\mathrm{K}_{2} \mathrm{CO}_{3}(\%)$ & 3 & 5 & 7 \\
\hline & Time (min) & 1 & 3 & 5 \\
\hline \multirow{2}{*}{$\begin{array}{l}2^{\text {nd }} \text { set: Effect of olive oil concentrations } \\
\text { and immersion time }\end{array}$} & Olive oil (\%) & 1 & 2 & 3 \\
\hline & Time (s) & 40 & 80 & 120 \\
\hline \multirow{2}{*}{$\begin{array}{l}3^{\text {rd }} \text { set: Effect of soy lecithin } \\
\text { concentrations and immersion time }\end{array}$} & Soy lecithin (\%) & 1 & 2 & 3 \\
\hline & Time (min) & 2 & 3 & 4 \\
\hline \multirow{2}{*}{$\begin{array}{l}4^{\text {th }} \text { set: } \text { Effect of sugar concentrations and } \\
\text { immersion time }\end{array}$} & Sugar $(\%)$ & 50 & 57 & 64 \\
\hline & Time (h) & 24 & 36 & 48 \\
\hline
\end{tabular}

Fig.1 Effect of potassium carbonate concentration and immersion time on drying time

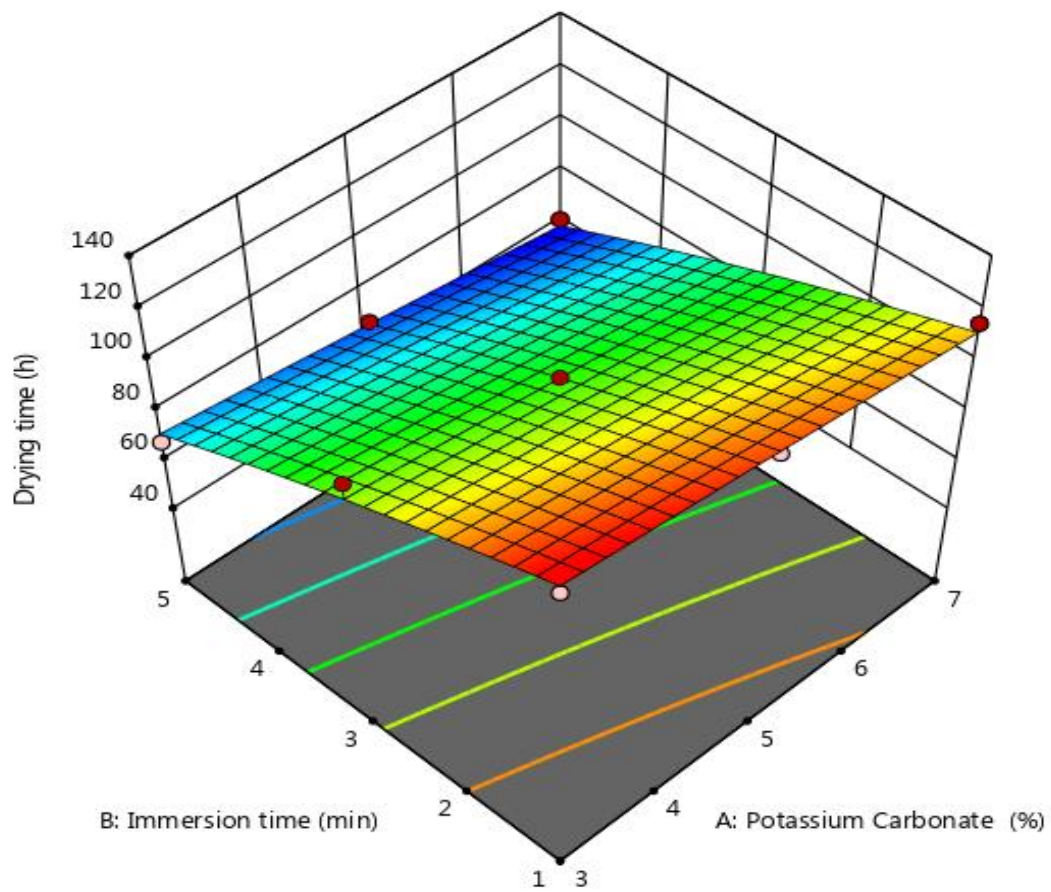


Fig.2 Effect of olive oil concentration and immersion time on drying time

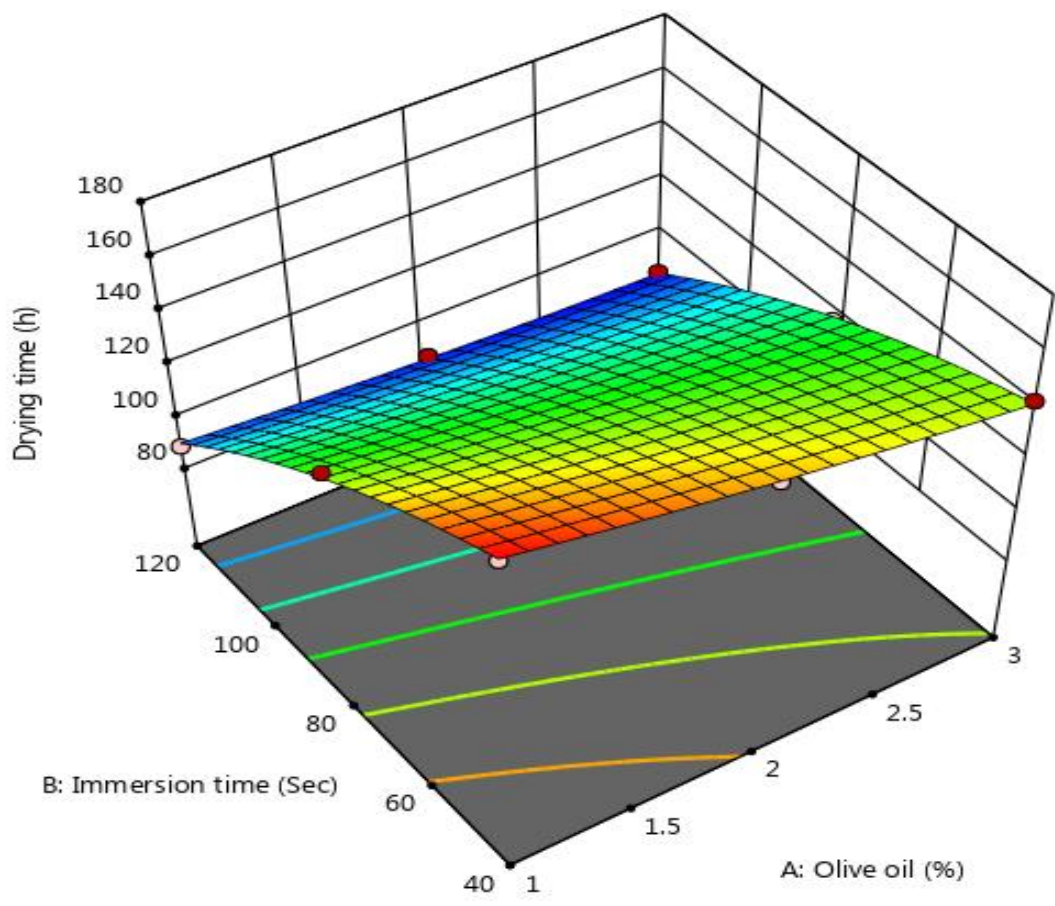

Fig.3 Effect of soy lecithin concentration and immersion time on drying time

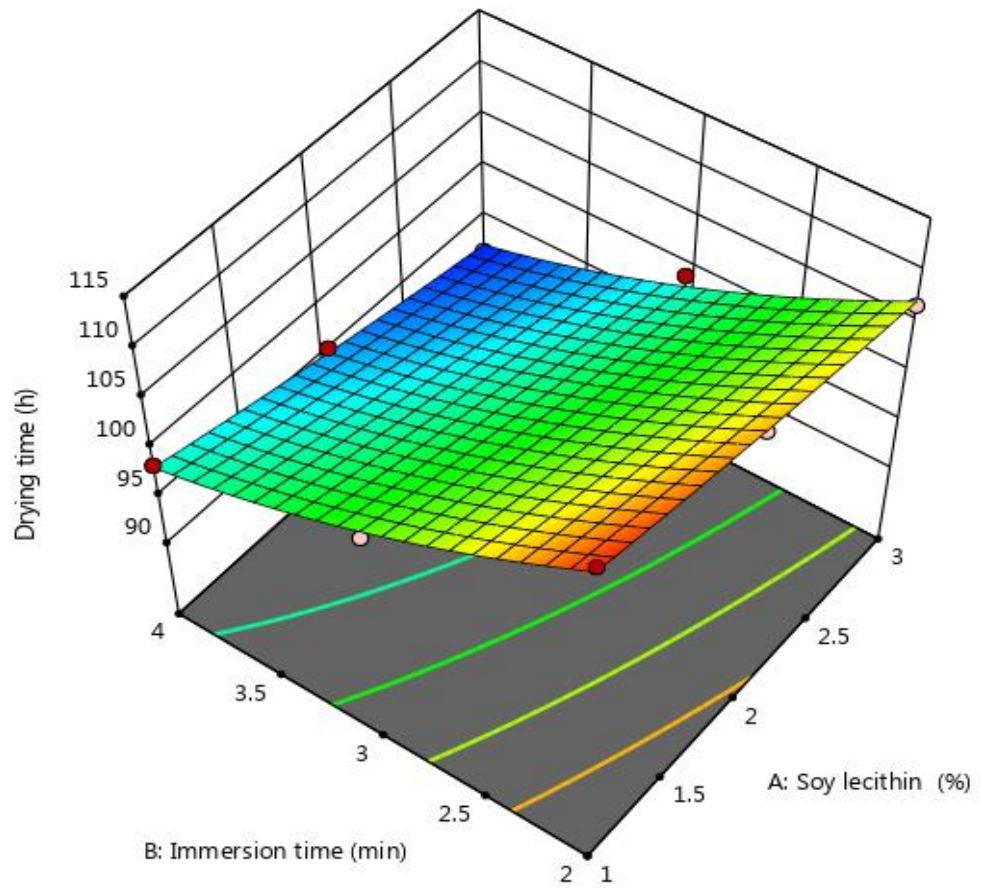


Fig.4 Effect of sugar concentration and immersion time on drying time

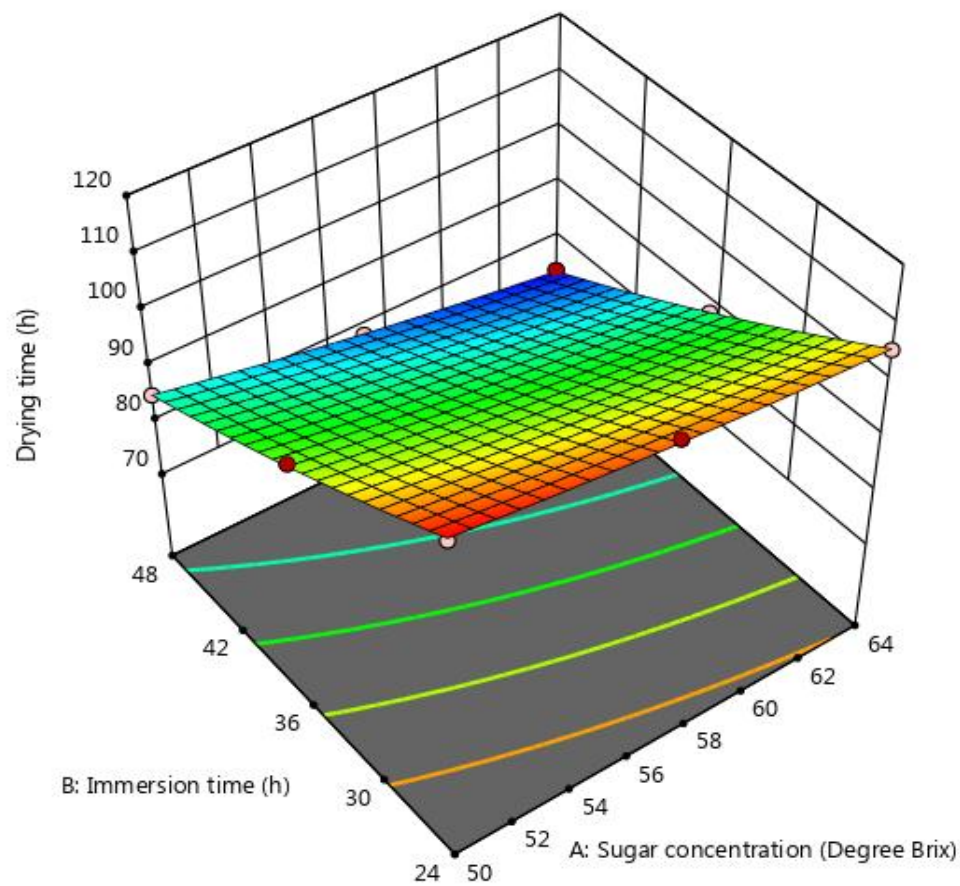

The drying time for the pretreated grapes decreased from $112.3 \mathrm{~h}$ to $73.5 \mathrm{~h}$ when sugar concentration increased from 50 to $64{ }^{\circ}$ Brix for immersion time ranging from 24 to $48 \mathrm{~h}$. An optimum sugar concentration and immersion time for the minimum drying time of $73.4 \mathrm{~h}$ was observed to be $64{ }^{\circ}$ Brix and 48 $\mathrm{h}$ respectively. Due to osmotic pressure in grapes, partial water was transferred to the sugar solution. Therefore, the drying time was lower due to partially dried grapes. The reason was also explained by Yongsawatdigul and Gunasekaran, 1996.

The Optimization process was employed to find out the best combination of process parameters i.e. concentration and immersion time of the different type of solution for the reduction of drying time of pre-treated grapes. They were dried in a hot air tray dryer at $50^{\circ} \mathrm{C}$ with an air velocity of $1 \mathrm{~m} / \mathrm{s}$. It was concluded that drying time reduced with an increase in solution concentration and immersion time. The minimum drying time of $61 \mathrm{~h}$ was found for the grapes treated with potassium carbonate concentration of $6.7 \%$ and immersion time of $5 \mathrm{~min}$.

\section{References}

Akanbi, C.T., Olumese, A.O., Taiwo, K. A., Ojo, A., Akinwande, B. A., 2003. Effect of blanching medium on drying and storage characteristics of pepper. Nigerian Drying Symposium Series, 1, 95-107.

Doymaz, I., 2007. Air-drying characteristics of tomatoes. J Food Eng, 78, 12911297.

Gabas, A. L., Menegalli, F. C., Telis Romero, J., 1999. Effect of chemical pretreatment on the physical dehydrated grapes. Dry Technol, 17: 1215-1226.

Kumari, S., Kumari, N. K., Jyothi, J., Lavanya, J. L., Swarnalatha, I., 2016. Study on drying behaviour of sapota (Manilkara Achras) in solar tray dryer 
and hot air cabinet dryer. IOSR Journal of Environmental Science, Toxicology and Food Technology, 10(4), 40-64.

Kingsly, R. P., Goyal, R. K., Manikantanand, M. R., Ilyas, S. M., 2007. Effects of pretreatments and drying air temperature on drying behaviour of peach slice. International Journal of Food Science and Technology, 42: 6569.

Pangavhane, D. R., Sawhney, R. L. and Sarsavadia, P. N., 1999. Effect of various dipping pretreatment on drying kinetics of Thompson seedless grapes. J. Food Eng, 39 (2): 211-216.

Patil, K., Vikas, Kumar, P. A., 2015. Osmo convective drying of sapota slices. Engineering and technology in India,
6(2):52-63.

Ranganna, S., 2000. Handbook of analysis and quality control for fruit and vegetable products. (3rd edn) Tata and McGrawHill, New Delhi.

Tunde-Akintunde, T. Y., Oyelade, O. J., Akintunde, B. O., 2014. Effect of drying temperatures and pre-treatments on drying characteristics, energy consumption, and quality of bell pepper. Agric Eng Int: CIGR, 6(2): 108-118.

Yongsawatdigul, J., Gunasekaran, S., 1996.

Microwave-vacuum drying of cranberries: Part 1. Energy use and efficiency. J Food Process Preserv., 20:121-143.

\section{How to cite this article:}

Jain Priti 2019. Production of Raisin from Pre-treated Grapes by Tray Drying. Int.J.Curr.Microbiol.App.Sci. 8(09): 1878-1884. doi: https://doi.org/10.20546/ijcmas.2019.809.217 